\title{
The Unitary Event Underlying Multiquantal EPSCs at a Hair Cell's Ribbon Synapse
}

\author{
Geng-Lin Li, ${ }^{1 \star}$ Erica Keen, ${ }^{2 \star}$ Daniel Andor-Ardó, ${ }^{2}$ A. J. Hudspeth, ${ }^{2}$ and Henrique von Gersdorff ${ }^{1}$ \\ ${ }^{1}$ The Vollum Institute, Oregon Health \& Science University, Portland, Oregon 97239, and ${ }^{2}$ Howard Hughes Medical Institute and Laboratory of Sensory \\ Neuroscience, The Rockefeller University, New York, New York 10065
}

\begin{abstract}
EPSCs at the synapses of sensory receptors and of some CNS neurons include large events thought to represent the synchronous release of the neurotransmitter contained in several synaptic vesicles by a process known as multiquantal release. However, determination of the unitary, quantal size underlying such putatively multiquantal events has proven difficult at hair cell synapses, hindering confirmation that large EPSCs are in fact multiquantal. Here, we address this issue by performing presynaptic membrane capacitance measurements together with paired recordings at the ribbon synapses of adult hair cells. These simultaneous presynaptic and postsynaptic assays of exocytosis, together with electron microscopic estimates of single vesicle capacitance, allow us to estimate a single vesicle EPSC charge of approximately $-45 \mathrm{fC}$, a value in close agreement with the mean postsynaptic charge transfer of uniformly small EPSCs recorded during periods of presynaptic hyperpolarization. By thus establishing the magnitude of the fundamental quantal event at this peripheral sensory synapse, we provide evidence that the majority of spontaneous and evoked EPSCs are multiquantal. Furthermore, we show that the prevalence of uniquantal versus multiquantal events is $\mathrm{Ca}^{2+}$ dependent. Paired recordings also reveal a tight correlation between membrane capacitance increase and evoked EPSC charge, indicating that glutamate release during prolonged hair cell depolarization does not significantly saturate or desensitize postsynaptic AMPA receptors. We propose that the large EPSCs reflect the highly synchronized release of multiple vesicles at single presynaptic ribbon-type active zones through a compound or coordinated vesicle fusion mechanism.
\end{abstract}

\section{Introduction}

The release of chemical transmitter at a neuromuscular junction displays several properties that simplified its analysis at that specialized synapse. A single motor nerve terminal has as many as a thousand presynaptic active zones, each of which contains a handful of docked synaptic vesicles. During normal neurotransmission, each docked vesicle's probability of release is low, $\sim 0.1-$ 0.2 , and independent of that of other vesicles. Invasion of the presynaptic terminal by an action potential evokes an excitatory endplate current that represents the summation of many smaller events that are nearly_-but not exactly-synchronous. Consistent with this hypothesis, lowering the probability of release by reducing the extracellular $\mathrm{Ca}^{2+}$ concentration reveals that each postsynaptic event represents an integer multiple of a fixed quantum. Like a spontaneous miniature endplate current of similar magnitude, this quantum is thought to represent the postsynap-

Received Jan. 30, 2009; revised March 31, 2009; accepted May 1, 2009.

This research was funded by National Institutes of Health Grants EY014043 and DC00241. G.-L.L. received a pilot grant from the National Organization for Hearing Research. H.v.G. received support from a Human Frontier Science Program grant; A.J.H. is an Investigator of the Howard Hughes Medical Institute. We thank the members of our research groups for helpful comments on this manuscript and W. Almers, W. Bialek, M. Frerking, C. Jahr, and L. Trussell for informative discussions.

${ }^{*} G$.-L.L. and E.K. contributed equally to this work.

Correspondence should be addressed to Henrique von Gersdorff, The Vollum Institute, 3181 Southwest Sam

Jackson Park Road, Oregon Health \& Science University, Portland, OR 97239. E-mail: vongersd@ohsu.edu. DOI:10.1523/JNEUROSCI.0514-09.2009

Copyright $\odot 2009$ Society for Neuroscience $\quad 0270-6474 / 09 / 297558-11 \$ 15.00 / 0$ tic response to the transmitter released from a single synaptic vesicle (Martin, 1977).

Although neurotransmission at synapses of the CNS shares the fundamental features of neuromuscular signaling, there are several important differences (Korn et al., 1993). Synaptic boutons are small and contain only one or a few active zones; as a consequence, the total number of vesicles released is small. The mechanism of transmitter release may vary between synapses or even at a particular synapse, with both complete exocytosis and kiss-and-run release of transmitter through a transitory fusion pore (Harata et al., 2001). The final feature, and the subject of the present communication, is so-called multiquantal release: individual EPSCs vary severalfold in amplitude, suggesting that the larger events represent the synchronous release of transmitter equivalent to that contained in several vesicles (Frerking et al., 1997). However, few studies have actually demonstrated this for spontaneous and evoked EPSCs (Tong and Jahr, 1994; Llano et al., 2000; Singer et al., 2004).

The ribbon synapses of vertebrate sensory receptors, including both neurons such as photoreceptors and epithelial cells such as hair cells, share numerous features with central nervous synapses (Heidelberger et al., 2005; Sterling and Matthews, 2005; Nouvian et al., 2006). In particular, recordings from afferent fibers of the eighth cranial nerve reveal that individual postsynaptic events, whether spontaneous or evoked, vary widely in size (Glowatzki and Fuchs, 2002; Keen and Hudspeth, 2006). Although the large events have been presumed to be multiquantal, it has not proven possible to demonstrate that each represents a multiple of 
a more basic response, that is, a quantum (Starr and Sewell, 1991; Siegel, 1992; Rossi et al., 1994). Several factors complicate this endeavor. Fluctuation analysis of hair cell capacitance measurements suggests a lower degree of multiquantal release by more mature hair cells than is estimated from EPSC recordings of afferent fibers (Neef et al., 2007), and large EPSCs might originate from single vesicles with higher glutamate concentrations (Henze et al., 2002). Furthermore, in contrast to photoreceptor ribbontype synapses (Pang et al., 2008), hair cell afferent fibers display $\mathrm{Ca}^{2+}$-independent mean EPSC amplitudes (Goutman and Glowatzki, 2007). In the present study, we have performed experiments meant to determine the quantal size underlying multiquantal EPSCs.

\section{Materials and Methods}

Physiological preparation. All procedures followed university-approved animal care protocols and guidelines. Adult bullfrogs (Rana catesbeiana) were sedated in an ice bath for $\sim 20 \mathrm{~min}$, then double-pithed and decapitated. Amphibian papillae were dissected in oxygenated artificial perilymph containing (in $\mathrm{mM}$ ): $120 \mathrm{NaCl}, 2 \mathrm{KCl}, 2 \mathrm{CaCl}_{2}, 3$ D-glucose, 1 creatine, and $5 \mathrm{HEPES}$ at pH $7.30\left(240 \mathrm{mOsmol} \cdot \mathrm{kg}^{-1}\right)$. Hair cells and their innervating afferent fibers were exposed by procedures described previously (Keen and Hudspeth, 2006). During recordings, the preparation was placed in HEPES-buffered perilymph or perfused continuously at $2-3 \mathrm{ml} / \mathrm{min}$ with bicarbonate-buffered perilymph continuously bubbled with $95 \% \mathrm{O}_{2}$ and $5 \% \mathrm{CO}_{2}$ and containing (in $\mathrm{mm}$ ): $95 \mathrm{NaCl}, 2 \mathrm{KCl}$, $2 \mathrm{CaCl}_{2}, 1 \mathrm{MgCl}_{2}, 3$ D-glucose, 1 creatine, $1 \mathrm{Na}$-pyruvate, and 25 $\mathrm{NaHCO}_{3}$ at pH $7.30\left(230 \mathrm{mOsmol} \cdot \mathrm{kg}^{-1}\right)$. Tetrodotoxin was added to the recording solution at a concentration of $1 \mu \mathrm{M}$ to block voltage-gated $\mathrm{Na}^{+}$channels.

Electrophysiology. Whole-cell recordings were obtained at room temperature with borosilicate glass pipettes pulled to resistances of 2-4 M $\Omega$ for hair cells and 8-10 $\mathrm{M} \Omega$ for afferent fibers. Internal solutions were composed of either (in mM): $110 \mathrm{CsCl}, 0.5 \mathrm{MgCl}_{2}, 2$ EGTA, $5 \mathrm{Na}_{2} \mathrm{ATP}$, and $10 \mathrm{HEPES}$ at $\mathrm{pH} 7.30\left(240 \mathrm{mOsmol} \cdot \mathrm{kg}^{-1}\right)$ or $80 \mathrm{Cs}$-gluconate, 20 $\mathrm{CsCl}, 10$ TEA-Cl, 2 EGTA, $3 \mathrm{Mg}$-ATP, $0.5 \mathrm{Na}-\mathrm{GTP}$, and $10 \mathrm{HEPES}$ at $\mathrm{pH}$ $7.30\left(240 \mathrm{mOsmol} \cdot \mathrm{kg}^{-1}\right)$. Whole-cell voltage-clamp recordings of afferent fibers and hair cells were performed with an Axopatch 200A amplifier (Axon Instruments) or a double EPC-9/2 amplifier (HEKA Elektronik).

Hair cells and afferent fibers were held at -80 or $-90 \mathrm{mV}$. Holding potentials were corrected for junction potentials $(4 \mathrm{mV}$ for the $\mathrm{CsCl}$ and $10 \mathrm{mV}$ for the gluconate solution) but not for the voltage drop across the uncompensated series resistance. The average series resistance $\left(R_{\mathrm{s}}\right)$ in the whole-cell mode was $18 \pm 6 \mathrm{M} \Omega$ for 18 hair cell recordings and $31 \pm 9$ $\mathrm{M} \Omega$ for 15 afferent fiber recordings. The voltage-clamp time constant was $\sim 100-200 \mu$ s for hair cell and afferent fiber recordings. Because the measured rise times of EPSCs and the voltage-clamp time constant of our recordings are similar, we may have overestimated the true rise times of EPSCs (Jonas et al., 1993; Wen and Brehm, 2005). An excessive series resistance could cause significant errors in EPSC amplitudes: amplitude distributions displayed a significant leftward shift if the series resistance exceeded $50 \mathrm{M} \Omega$ (see supplemental Fig. 1, available at www.jneurosci.org as supplemental material), so we excluded from analysis all afferent fiber recordings meeting that criterion.

For iontophoretic experiments, the preparation was bathed in a $\mathrm{Ca}^{2+}$ free solution containing $0.1 \mathrm{~mm}$ EGTA. Borosilicate glass pipettes were pulled to resistances of $80-100 \mathrm{M} \Omega$ when filled with $0.5 \mathrm{M} \mathrm{CaCl}_{2}$ at $\mathrm{pH}$ 7.0. A steady-state holding current was applied to prevent diffusional leakage of $\mathrm{Ca}^{2+}$ from the pipette. Iontophoretic currents of 1-3 nA were delivered with an Axoclamp-2A amplifier (Axon Instruments). Stimuli were presented and data acquired with programs written in LabVIEW (National Instruments) or with Pulse software (HEKA). Currents were low-pass filtered at $8 \mathrm{kHz}$ and sampled at $10 \mu$ s intervals or filtered at 2 $\mathrm{kHz}$ and sampled at $50 \mu$ s intervals.

Statistical analysis of coincident EPSCs. We used a Poisson process to model the generation of events. The Poisson distribution gives the prob- ability of single or multiquantal events. The likelihood of a record with a set $\left\{a_{\mathrm{i}}\right\}$ of $m$ events of nonzero amplitude is

$$
\begin{aligned}
L & =e^{-(M-m) \lambda} \prod_{i=1}^{m} \sum_{n=1}^{\infty} \frac{e^{-\lambda} \lambda^{n} q_{n}\left(a_{i}\right)}{n !} \\
& =e^{-M \lambda} \prod_{i=1}^{m} \sum_{n=1}^{\infty} \frac{\lambda^{n} q_{n}\left(a_{i}\right)}{n !},
\end{aligned}
$$

in which $M=T$ / $\Delta t$ is the length $T$ of the record divided by the deconvolution resolution $\Delta t$, and $q_{\mathrm{n}}(a)$ gives the likelihood of an event of size $a$ being composed of $n$ events. The tension between the rate $\lambda$ determined by the silence as opposed to the mean amplitude of events is represented by competition between the initial exponential term and the product term. Significant jitter in the generation and detection of amplitudes $\left\{a_{\mathrm{i}}\right\}$ means that $q$ tends to be broad: most of the histograms we examined did not display discernable peaks at integer multiples of the quantum. We require that both mean and variance of $q_{\mathrm{n}}$ should scale with $n$. To enforce positivity of event sizes - there are no EPSCs with current flowing in the wrong direction-we used $q_{\mathrm{n}}(a)$ : $\operatorname{Gamma}\left(n \alpha^{2} \beta, \alpha \beta\right)$, in which $\alpha$ is the mean and $\beta$ is the accuracy (inverse variance) when $n=1$. We also performed the calculation with $q_{\mathrm{n}}(a)$ : $\operatorname{Normal}(n \alpha, n / \beta)$, but this change did not make a significant difference.

The model admits two kinds of solutions, corresponding to the null and alternate hypotheses. The latter intrinsically requires an additional parameter describing the rate at which orchestrated fusion occurs. However, by using a family of models that spans both null and alternate hypotheses, we simplify the problem (Gelman et al., 2004). When $\alpha$ is small and $\beta$ is large, multiquantal events are explained by the coincidence of multiple small events of size $\alpha$. Conversely, when $\alpha$ is large and $\beta$ is small, it is the action of orchestrated release that explains multiquantal events. We marginalize over $\lambda$ and $\beta$, leaving the marginal likelihood as a function of $\alpha$ only. Optimizing $\alpha$ gives the maximum likelihood solution at $\hat{\alpha}$ from the family of models. The null hypothesis is simply the special case of $\alpha=1$ quantum. The ratio $L(\alpha=\hat{\alpha}) / L(\alpha=1)$ can be interpreted as evidence in favor of the alternate hypothesis.

Capacitance measurements and data analysis. Whole-cell membrane capacitance measurements from hair cells were performed under voltage clamp with the "Sine + DC" method (Lindau and Neher, 1988) using a double EPC9/2 amplifier and Pulse software (HEKA). Pipettes were coated with wax to minimize stray capacitance and to achieve better pipette capacitance compensation. A $1 \mathrm{kHz}$ sinusoidal command voltage of $50 \mathrm{mV}$ peak-to-peak magnitude was superposed on the hair cell holding potential of $-90 \mathrm{mV}$. The resulting current response was used to calculate presynaptic capacitance, membrane resistance, and series resistance with the Pulse software emulator of a lock-in amplifier (Gillis, 2000).

Data analysis was performed with Mini Analysis (Synaptosoft; Jaejin Software), Excel (Microsoft), Mathematica (Wolfram Research), and IGOR Pro (WaveMetrics). Spontaneous EPSC events were also detected and analyzed with software written by Dr. H. Taschenberger (Max Planck Institute for Biophysical Chemistry, Göttingen, Germany) using an optimally scaled template method (Clements and Bekkers, 1997). All average results are reported as means \pm SDs for $n$ different cells. For example, each mean peak EPSC amplitude \pm SD was obtained from recordings from $n$ afferent fibers. For each fiber, EPSC events were measured and an average peak value was calculated from all events of that fiber. The reported mean peak EPSC was then the average over the EPSC values from the $n$ fibers, and the SD was calculated from those $n$ values. Similarly, a coefficient of variation was calculated for each fiber recording and the mean coefficient of variation was an average of the individual values from the $n$ fibers (Prism 4.0; GraphPad).

Electron microscopy. The preparative techniques for the electron microscopic observations have been described previously (Keen and Hudspeth, 2006). 


\section{Results}

The amphibian papilla, the principal auditory receptor of the bullfrog, provides a useful experimental preparation for the investigation of neurotransmission at an adult ribbon synapse (Keen and Hudspeth, 2006). In the central portion of this organ, where afferent fibers are tuned to frequencies of $400-800 \mathrm{~Hz}$ (Smotherman and Narins, 2000), each hair cell contacts one or a few nerve fibers that may readily be visualized by differential interference contrast optics. At each of a hair cell's several active zones, synaptic vesicles are clustered around a roughly ellipsoidal presynaptic dense body or synaptic ribbon. On release from vesicles, the excitatory neurotransmitter glutamate activates AMPA receptors in the postsynaptic membrane. It is straightforward to record by the wholecell, tight-seal technique from either a presynaptic hair cell or a postsynaptic nerve fiber; simultaneous recordings from both elements of the synapse are also possible.

\section{Spontaneous EPSCs}

Even in the absence of stimulation, afferent fibers displayed a brisk rate of spontaneous EPSCs (Fig. 1A). Recordings from nine fibers revealed postsynaptic events at a rate of $60 \pm 28 \mathrm{~s}^{-1}$ and of widely varying magnitude. In determining the amplitude distribution of spontaneous EPSCs, we found that a low access resistance of the recording electrode, preferably $<40$ $\mathrm{M} \Omega$, was critical: the voltage error and filtering produced by a greater series resistance systematically reduced the number of large events and skewed the amplitude distribution toward smaller events (supplemental Fig. 1, available at www.jneurosci. org as supplemental material). In satisfactory recordings with a stable low series resistance, the amplitude distribution of spontaneous EPSCs was typically well fit with a Gaussian function (Fig. $1 \mathrm{~B})$. The amplitude of spontaneous EPSCs from seven fibers held at a membrane potential of $-90 \mathrm{mV}$ averaged $-129 \pm 24 \mathrm{pA}$, and the coefficient of variation was 0.35 .

Regardless of amplitude, most spontaneous EPSCs displayed smooth onset and decay phases (Fig. 1C) without the interruptions characteristic of imperfectly superposed quantal events at the neuromuscular junction. Although lowering the ambient temperature from $22^{\circ} \mathrm{C}$ to $15^{\circ} \mathrm{C}$ desynchronizes release at the neuromuscular junction (Martin, 1977), this manipulation failed to reveal inflection points in the rise or decay phases of EPSCs (supplemental Fig. 2, available at www. jneurosci.org as supplemental material). For the average of 10 events with amplitudes of $-100 \pm 1 \mathrm{pA}$ from each of nine fibers, the $10-90 \%$ rise time was $0.25 \pm 0.01 \mathrm{~ms}$ at $22^{\circ} \mathrm{C}$. In recordings from eight fibers, the decay phase of EPSCs was well fit by a single exponential function with an average time constant of $0.48 \pm 0.05 \mathrm{~ms}$ (Fig. $1 D$ ).

If larger events arise from the superposition of multiple quantal events, they might be expected to display broadening because of slight differences in the times at which their constituent vesicles undergo exocytosis (Wall and Usowicz, 1998; Wen and Brehm, 2005). On the contrary, the temporal characteristics of EPSCs were independent of their amplitudes (Fig. 1D). An anal-
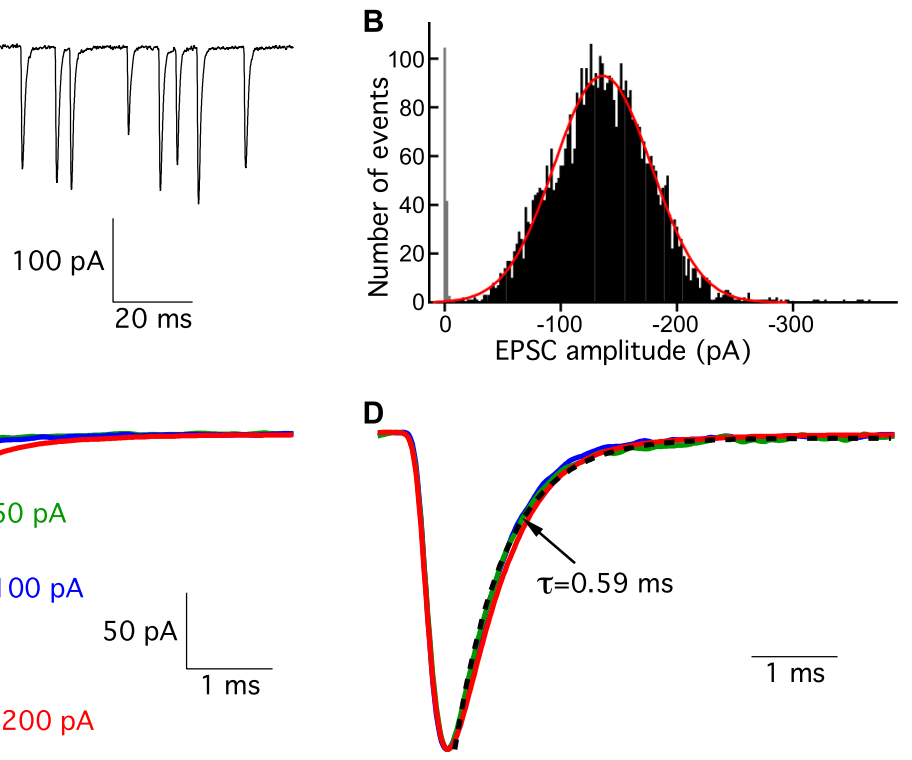

$200 \mathrm{pA}$

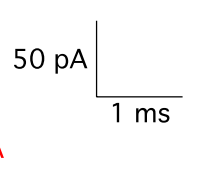

Spontaneous EPSCS. $\boldsymbol{A}$, Spontaneous EPSCs recorded from an afferent fiber exhibit a broad range of amplitudes. $\boldsymbol{B}$ decay phases. $\boldsymbol{D}$, Normalization of the three groups of EPSC in C reveals that they have similar kinetics. The dashed black line is a

ysis of seven fiber recordings showed no significant difference in the waveforms of small and large EPSCs. Unlike the evoked postsynaptic events at the neuromuscular junction, then, the putatively multiquantal events at the hair cell's synapse reveal no substructure indicative of independent but nearly coincident vesicle fusions.

\section{AMPA receptor antagonists}

If large EPSCs represent multiquantal fusions at individual presynaptic active zones, they should generate a higher concentration of glutamate in the synaptic cleft than smaller, uniquantal events. A low-affinity, rapidly dissociating AMPA receptor antagonist, such as $\gamma$-D-glutamylglycine ( $\gamma$-DGG), may be used to test whether larger EPSCs reflect the presence of more cleft glutamate. If this is the case, $\gamma$-DGG will block small EPSCs more effectively than large ones (Wadiche and Jahr, 2001; Singer et al., 2004; Christie and Jahr, 2006).

When we applied $\gamma$-DGG, all EPSCs were reduced in amplitude compared with those recorded in control solution (Fig. 2 A). We determined the average amplitudes of two subsets of events (Fig. 2A): those with amplitudes at the tenth percentile $\left(\mathrm{E}_{10 \%}\right.$ values within $\pm 2 \mathrm{pA}$ ) and those with amplitudes at the ninetieth percentile $\left(\mathrm{E}_{90 \%}\right.$ values within $\left.\pm 2 \mathrm{pA}\right)$. We normalized $\mathrm{E}_{90 \%}$ events in $\gamma$-DGG to their counterparts in control solution. Normalizing $\mathrm{E}_{10 \%}$ events by the same ratio revealed that $\mathrm{E}_{10 \%}$ events were blocked to a greater extent by $\gamma$-DGG (Fig. $2 B$ ).

As a control, we applied NBQX, a high-affinity antagonist of AMPA receptors. In the presence of NBQX, $\mathrm{E}_{90 \%}$ and $\mathrm{E}_{10 \%}$ events were blocked to a similar extent (Fig. 2C). The average normalized ratio of $\mathrm{E}_{10 \%} / \mathrm{E}_{90 \%}$ was significantly smaller for $\gamma$-DGG versus control (six cells) but not for NBQX versus control (five cells) (Fig. 2D). Furthermore, the average frequency of EPSCs did not change after $\gamma$-DGG or NBQX application (control, $94 \pm 86 \mathrm{~s}^{-1}$; $\gamma$-DGG, $102 \pm 80 \mathrm{~s}^{-1}$, six fibers; and control, $67 \pm 58 \mathrm{~s}^{-1}$; NBQX, $68 \pm 52 \mathrm{~s}^{-1}$, five fibers), indicating that these drugs do not exert a significant presynaptic effect. These results suggest 

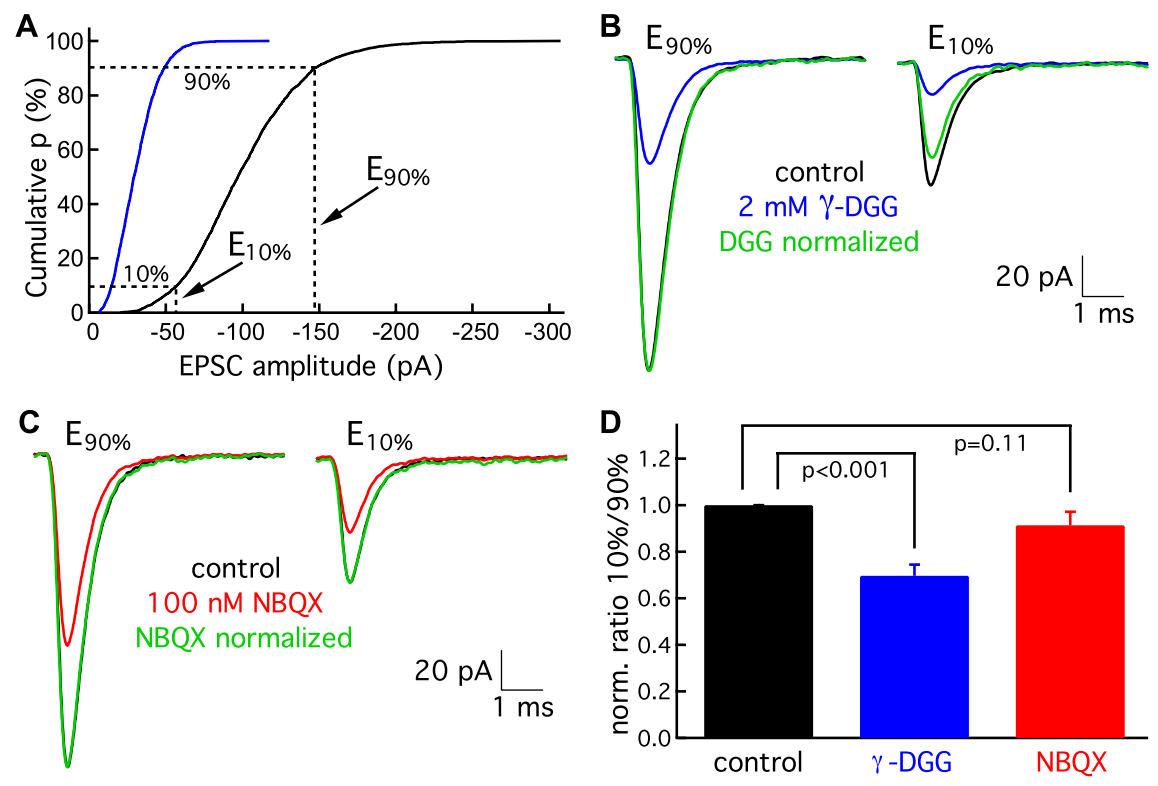

Figure 2. Differential block of EPSCs by $\gamma$-DGG. $A$, The cumulative amplitude distribution of EPSCs allows the selection of events in the smallest decile $\left(E_{10 \%}\right)$ and those in the largest decile $\left(E_{90 \%}\right)$. The blue trace shows that $2 \mathrm{~mm} \gamma$-DGG, a low-affinity AMPA receptor antagonist, reduces the amplitudes of both small and large events. $\boldsymbol{B}$, After averaging $10-20$ events each from the $\mathrm{E}_{90 \%}$ and $\mathrm{E}_{10 \%}$ classes, events within $\pm 2 \mathrm{pA}$, under control circumstances (black) or in the presence of 2 mm $\gamma$-DGG (blue), the result for the $\mathrm{E}_{90 \%}$ class in $\gamma$-DGG is normalized to that in control solution (green). When the same normalization factor is applied to the $E_{10 \%}$ results, that for $\gamma$-DGG (green) is substantially smaller than that in control solution (black), indicating that $\gamma$-DGG blocks smaller EPSCs more efficaciously. C, In a comparison of EPSCs in control solution (black) with those in $100 \mathrm{~nm} \mathrm{NBQX} \mathrm{(red),}$ normalization shows that events in the $\mathrm{E}_{90 \%}$ and $\mathrm{E}_{10 \%}$ classes are blocked to a similar extent (green). $\boldsymbol{D}$, When the ratios $\left(\mathrm{E}_{10 \%}\right)$ $E_{90 \%}$ ) for results in $\gamma$-DGG (blue) and NBQX (red) are normalized to their corresponding controls, the normalized ratio is significantly reduced by $\gamma$-DGG (6 cells) but not by NBQX (5 cells). Statistical significance was evaluated with a paired Student's $t$ test.

that the variability in EPSC amplitude is dominated by differences in presynaptic glutamate release rather than in the properties of postsynaptic afferent fibers.

\section{$\mathrm{Ca}^{2+}$ iontophoresis}

Because afferent fibers in the amphibian papilla form multiple terminal branches onto hair cells, we ordinarily sample release events from several presynaptic active zones in our postsynaptic recordings. Thus, large EPSCs could in principle represent the simultaneous fusion of vesicles at distinct synaptic ribbons. To determine whether large events can originate from a single active zone, we bathed the preparation in a zero $\mathrm{Ca}^{2+}$ solution to silence spontaneous activity and applied $\mathrm{Ca}^{2+}$ iontophoretically with a $\mathrm{Ca}^{2+}$-filled pipette. Control experiments with fluorescent $\mathrm{Ca}^{2+}$ indicators confirmed that iontophoretic application was highly localized to the region near the application pipette (data not shown). Brief pulses of $\mathrm{Ca}^{2+}$ were sufficient to evoke EPSCs similar in amplitude to the largest spontaneous EPSCs recorded from the same fiber in control solution (Fig. 3). Similar results were observed in three recordings. These experiments demonstrate that large EPSCs can arise from a single active zone and suggest that large spontaneous events originate from single synaptic ribbons.

\section{Effect of hair cell hyperpolarization}

In an effort to demonstrate quantal components in the putatively multiquantal events, we next attempted to reduce the cytoplasmic concentration of $\mathrm{Ca}^{2+}$, the presumed trigger for synaptic release, by presynaptic hyperpolarization during paired recordings. We compared spontaneous EPSCs before and after lowering the membrane potential of the hair cell from its control resting three synaptic vesicles.

level of approximately $-60 \mathrm{mV}$ to -80 $\mathrm{mV}$ or $-90 \mathrm{mV}$. Hyperpolarizing a hair cell reduced the frequency of EPSCs and selectively eliminated large events (Fig. 4). The EPSC amplitude during hyperpolarization of 10 hair cells to $-90 \mathrm{mV}$ fell to a mean value of $-57 \pm 13 \mathrm{pA}$. In the seven recordings with sufficient events for analysis, the coefficient of variation averaged 0.29 , a value close to those obtained at the neuromuscular junction (Del Castillo and Katz, 1954) and at individual central synapses (Forti et al., 1997; for review, see Auger and Marty, 2000; Crowley et al., 2007).

The amplitude distributions of spontaneous EPSCs under control conditions do not display modal peaks (Figs. $1 B, 4 C$ ). Similar results are found at other CNS synapses with multiple release sites (but see Jonas et al., 1993; Silver et al., 1996). At these synapses, lowering release probability also reduces the average EPSC amplitude. To determine whether our spontaneous EPSC distributions might contain multiquantal events, we fitted them with sums of Gaussians of the putative quantal event that predominates during hair cell hyperpolarization to $-90 \mathrm{mV}$ (data not shown). The results of these analyses were consistent with the possibility that most spontaneous events are multiquantal, reflecting the simultaneous fusion of two to

To determine the corresponding value for the postsynaptic charge transfer, we also calculated the integrals of the EPSCs recorded during hair cell hyperpolarization. Because the waveforms of EPSCs do not vary with amplitude (Fig. 1D), the charge transfer distribution displayed a similar Gaussian profile with a mean value of $-50.2 \pm 2.8 \mathrm{fC}$ when the hair cell was held at -90 $\mathrm{mV}$.

\section{Possible superposition of events}

Could large EPSCs be caused by the coincident, but independent, fusion of single quanta? If fusion events are independent, the probability of coincidences depends only on the ability of the recording apparatus and our deconvolution algorithm to resolve individual EPSCs. A conservative estimate of the resolution of our maximum entropy deconvolution algorithm at typical noise levels is that it separates events as close as $0.5 \mathrm{~ms}$. In a $10 \mathrm{~s}$ stretch of spontaneous activity in which we encountered 443 EPSCs, we would, therefore, expect fewer than 10 to occur sufficiently close together to register as multiquantal events. Yet more than $75 \%$ of the 443 events are large, leading to a mean of two quanta. Is coincidence of independent events a good explanation for this? Intuitively, it seems not: the distribution of silences suggests a low rate of coincidence, $\sim 2 \%$ for this record, yet the majority of the EPSCs are larger than the putatively quantal events.

Although we lack an understanding of the mechanism of vesicle release, we can consider two general modes of explanation. Our null hypothesis is that a single process generates independent events that occasionally coincide. Alternatively, there could be an additional process that orchestrates release such that multiquantal events occur most of the time. Although coincidences would 

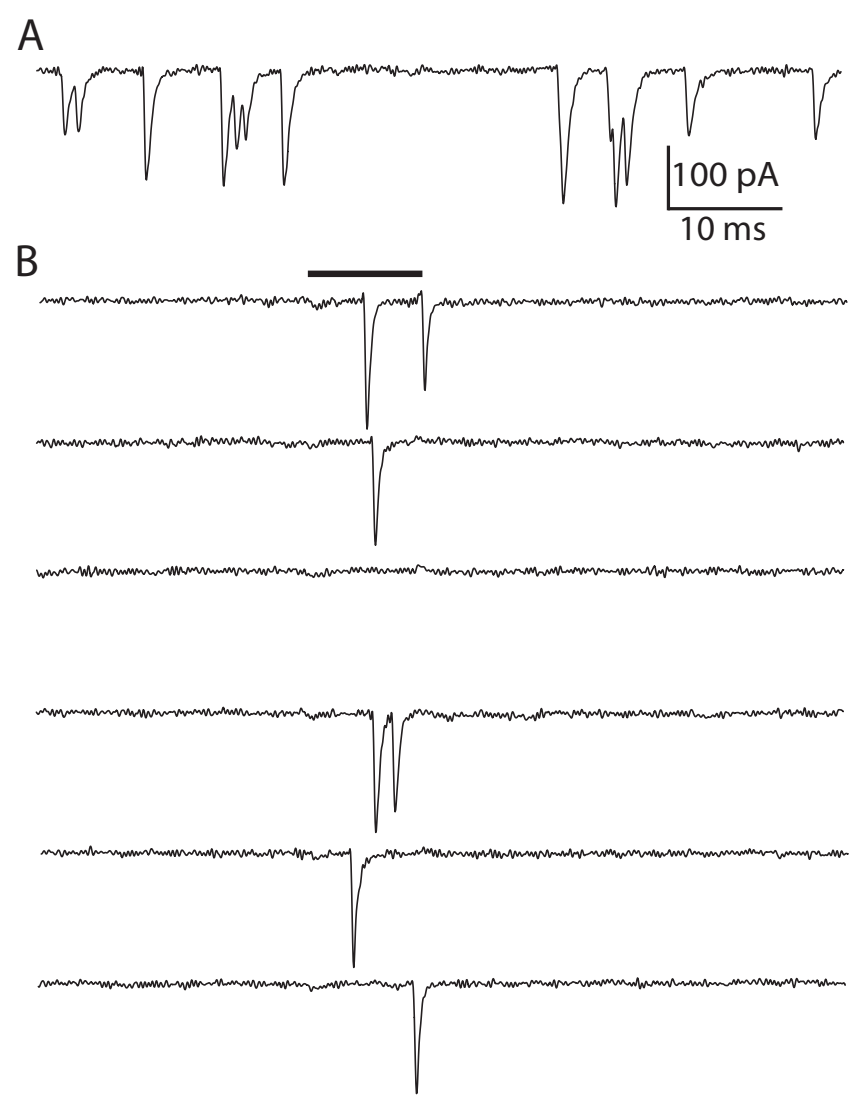

Figure 3. $\mathrm{Ca}^{2+}$ iontophoresis onto a single active zone. $A$, Under control recording conditions, spontaneous EPSCs in an afferent fiber recording display a wide range of amplitudes. $\boldsymbol{B}$, When the preparation is bathed in a zero $\mathrm{Ca}^{2+}$ solution, the spontaneous events are suppressed. $\mathrm{A} 10 \mathrm{~ms}$ local iontophoresis of $\mathrm{Ca}^{2+}$ (black bar) onto a putatively single synapse evokes EPSCs as large as those recorded from the same fiber in control solution. Failures to evoke EPSCS occurred for $37 \%$ of the iontophoretic applications at this site.

still occur under the alternate hypothesis, the additional cooperative process would explain most of the large events. When we compared the marginal likelihoods of these two hypotheses for the record described above, the weight of evidence in favor of the alternative explanation was a formidable $9 \cdot 10^{157}$. A similar calculation for a segment of the same length but containing only one-tenth the number of events yielded a factor of $8 \cdot 10^{13}$. These results confirm the intuitive impression that large EPSCs do not arise from the superposition of independently released quanta.

\section{$\mathrm{Ca}^{2+}$ dependence of release}

To investigate the voltage and $\mathrm{Ca}^{2+}$ dependence of multiquantal release, we performed paired recordings in which the membrane potential of the hair cell was progressively depolarized from a holding potential of $-90 \mathrm{mV}$. By comparing the resulting EPSC amplitudes in the presence of 2 mM EGTA, our standard presynaptic $\mathrm{Ca}^{2+}$ buffer, or of $10 \mathrm{~mm}$ BAPTA, a fast $\mathrm{Ca}^{2+}$ buffer, we were able to distinguish between the effects of voltage and $\mathrm{Ca}^{2+}$ on release.

During hyperpolarization to membrane potentials more negative than $-70 \mathrm{mV}$, EPSCs were infrequent and averaged approximately $-55 \mathrm{pA}$ in amplitude (Fig. $5 A, B$ ). Depolarization to potentials between -70 and $-65 \mathrm{mV}$ in the presence of EGTA raised the frequency of events and increased their average size to $-106 \pm 32 \mathrm{pA}$ (434 events from six cells). In contrast, the same depolarization in the presence of BAPTA resulted in EPSCs with an average size of $-59 \pm 20 \mathrm{pA}$ (80 events from five cells) (Fig. $5 C)$. Hair cell depolarization per se is, therefore, not the determining factor for triggering multiquantal release (Zhang and Zhou, 2002).

The effect of $\mathrm{Ca}^{2+}$ chelation by BAPTA could be overcome by greater depolarization. In the voltage range of $-55 \mathrm{mV}$ to -50 $\mathrm{mV}$, EPSCs reached a mean amplitude of $-151 \pm 38 \mathrm{pA}(1153$ events from five cells). This response was similar to that of $-125 \pm 43 \mathrm{pA}$ (480 events from five cells) for hair cells containing EGTA and held between $-65 \mathrm{mV}$ and $-60 \mathrm{mV}$. These results imply that multiquantal release requires an increase in the intracellular free $\mathrm{Ca}^{2+}$ concentration. The inability of $10 \mathrm{~mm}$ BAPTA to completely block release during greater hair cell depolarization implies that $\mathrm{Ca}^{2+}$ channels lie in close proximity to exocytosiscompetent vesicles. This conclusion accords with previous studies showing a tight colocalization of synaptic ribbons, the organelles presumably involved in exocytosis, with the sites of $\mathrm{Ca}^{2+}$ influx into hair cells (Issa and Hudspeth, 1994; Zenisek et al., 2003).

To confirm that $\mathrm{Ca}^{2+}$-channel activation is necessary to elicit multiquantal release, we blocked $\mathrm{Ca}^{2+}$ channels with $0.4 \mathrm{mM}$ $\mathrm{Cd}^{2+}$ (Fig. 6C). For six afferent fiber recordings, the average amplitude of 398 spontaneous EPSCs was $-54 \pm 8 \mathrm{pA}$, and their rate was greatly reduced. In two of these recordings, removing the $\mathrm{Cd}^{2+}$ restored large spontaneous EPSCs. In the other four recordings, an increasing series resistance during the very slow washout of $\mathrm{Cd}^{2+}$ precluded the demonstration of reversibility. Postsynaptic currents elicited by glutamate ejection onto the afferent fibers were not significantly different in the presence of 0.4 $\mathrm{mM} \mathrm{Cd}^{2+}$ (data not shown).

These results demonstrate that both the amplitude and the frequency of EPSCs are $\mathrm{Ca}^{2+}$-dependent at an adult hair cell synapse. Conditions of high release probability promote multivesicular release at several synapses (Wadiche and Jahr, 2001; Singer et al., 2004; Christie and Jahr, 2006). In contrast, although the EPSC frequency was $\mathrm{Ca}^{2+}$-dependent, the distribution of spontaneous EPSC amplitudes and the mean evoked EPSC amplitude were found not to be $\mathrm{Ca}^{2+}$-dependent at the synapses of juvenile rat inner hair cells (Glowatzki and Fuchs, 2002; Goutman and Glowatzki, 2007). We suggest that the immature nature of those synapses may explain these differing results, for synaptic properties change significantly during mammalian postnatal development (Wall and Usowicz, 1998; Johnson et al., 2005).

\section{Presynaptic capacitance measurements}

During exocytosis, the incorporation of vesicular membrane into the plasma membrane transiently increases the capacitance of secretory cells (Neher and Marty, 1982; Angleson and Betz, 1997) and synaptic terminals (Heidelberger et al., 1994; von Gersdorff and Matthews, 1994; Sun and Wu, 2001; Hallermann et al., 2004). To obtain an estimate of the rate of vesicle fusion, we stimulated exocytosis by depolarizing a hair cell from a holding potential of -90 to $-30 \mathrm{mV}$ and measured the change in membrane capacitance. We simultaneously recorded the presynaptic $\mathrm{Ca}^{2+}$ current borne by L-type channels (Parsons et al., 1994; Rodriguez-Contreras and Yamoah, 2001; Schnee and Ricci, 2003; Edmonds et al., 2004).

At the holding potential of $-90 \mathrm{mV}, 15$ hair cells from the bullfrog's amphibian papilla displayed an average capacitance of $11.6 \pm 1.5 \mathrm{pF}$. A $500 \mathrm{~ms}$ depolarization increased their capacitance by $99 \pm 39 \mathrm{fF}$. Because neither the series resistance nor the membrane resistance changed after the depolarization, the capacitance measurement was devoid of conductance artifacts (Fig. 6A) (Horrigan and Bookman, 1994). The capacitance change 
A
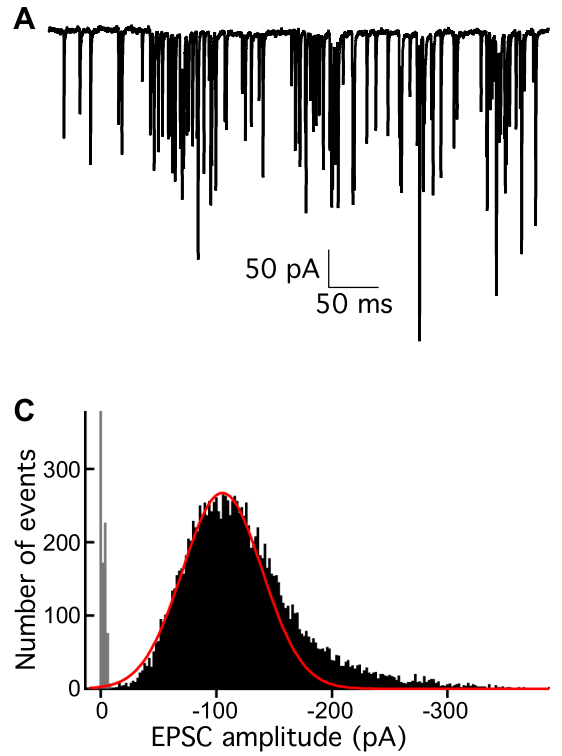

B

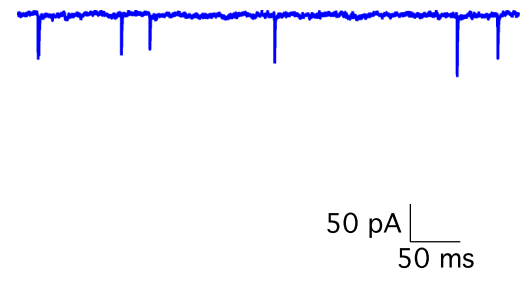

D

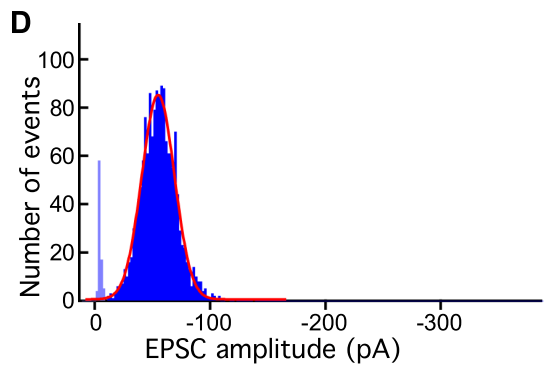

Figure 4. Presynaptic hyperpolarization during paired recordings. $\boldsymbol{A}$, Spontaneous EPSC events originating from an unclamped hair cell display a large range of amplitudes. $\boldsymbol{B}$, Voltage clamping the presynaptic hair cell to $-90 \mathrm{mV}$ eliminates all large events recorded from the same afferent fiber and reduces the frequency of the events. $\boldsymbol{C}$, The rising phase of the amplitude distribution of 13,791 EPSCs from $\boldsymbol{A}$ was fit with a Gaussian function. Skewing of the distribution by large events occurred in a minority of recordings. The Gaussian fit yields a mean value of $-105 \mathrm{pA}$, smaller than the value of $-125 \mathrm{pA}$ obtained from the average of all the events. $\boldsymbol{D}$, Holding the hair cell at $-90 \mathrm{mV}$ shifted the amplitude distribution of 1542 EPSCs to a peak at $-57 \mathrm{pA}$. The distribution is well fit by a Gaussian function with a mean value of $-55 \mathrm{pA}$.

increased monotonically for hair cell depolarizations from 10 to $1000 \mathrm{~ms}$ (Fig. 6B). Because the capacitance returned to its baseline value with an exponential time constant of $\sim 11 \mathrm{~s}$ (data not shown), capacitance measurements made within 100-500 ms of the depolarizing pulse should not be significantly affected by membrane retrieval. The extracellular application of 200-400 $\mu \mathrm{M} \mathrm{Cd}{ }^{2+}$ blocked both the presynaptic $\mathrm{Ca}^{2+}$ current and the capacitance increase in four experiments (Fig. 6C), indicating that depolarization-evoked vesicle fusion requires $\mathrm{Ca}^{2+}$ influx (Parsons et al., 1994).

\section{Paired presynaptic and postsynaptic recordings}

Simultaneous recordings from a hair cell and its innervating fiber permitted us to correlate the rate of vesicle fusion, as manifested by a change in the presynaptic capacitance, with the rate of transmitter release, as measured by an evoked postsynaptic current. Presynaptic depolarizations that produced robust capacitance changes also resulted in large postsynaptic responses with highly overlapping EPSCs (Fig. 7A). As a measure of the postsynaptic response, we therefore measured the cumulative postsynaptic charge transfer or integral of the postsynaptic current.

During a sustained depolarization, the postsynaptic charge transfer first rose briskly, then continued to increase at a lower, nearly constant rate (Fig. $7 B$ ). Averaged over 11 recordings, the kinetics of the postsynaptic response accorded with that of the average presynaptic capacitance increase in six hair cells. These results are consistent with exocytosis from a readily releasable pool of vesicles followed by a reserve pool (Moser and Beutner, 2000; Lenzi et al., 2002; Edmonds et al., 2004; Spassova et al., 2004; Griesinger et al., 2005; Johnson et al., 2005; Schnee et al., 2005; Rutherford and Roberts, 2006). The close agreement between postsynaptic charge transfer and capacitance increases suggests that neither desensitization nor saturation of AMPA receptors occurs to a significant degree at this synapse (Wölfel et al., low, this value can be used to obtain an estimate of the quantal response.

One qualification of these recordings is that the release of some transmitter by a rapid kiss-and-run mechanism could artifactitiously lower our estimate of the capacitance increase associated with a given postsynaptic response. Optical measurements from isolated retinal bipolar cells and hair cells suggest, however, that most release at synaptic ribbons involves the complete fusion of vesicles (Llobet et al. 2003; Zenisek et al., 2003).

\section{Electron microscopy and the capacitance of single vesicles}

To estimate the capacitance change expected from fusion of a single synaptic vesicle, we conducted electron microscopy on hair cells in the region of the amphibian papilla from which our physiological results originated. At 23 active zones, we measured the dimensions of 119 vesicles whose perimeters were bounded completely by trilaminar membrane and which, therefore, lay mainly or entirely within the $70 \mathrm{~nm}$ sections (Fig. $8 \mathrm{~A}$ ). The geometric mean of the greatest and least diameters, measured at the center of the trilaminar structure, was $37.6 \pm 4.5 \mathrm{~nm}$; the arithmetic mean was $37.8 \pm 4.5 \mathrm{~nm}$. The amplitude distribution was well fit by a Gaussian function with mean value of $40.3 \mathrm{~nm}$ (Fig. $8 \mathrm{~B}$ ). The synaptic vesicles at this synapse are therefore of dimensions similar to those at the ribbon synapses of other hair cells in frog, turtle, and mouse (Lenzi et al., 1999; Schnee et al., 2005; Neef et al., 2007). Assuming that the specific membrane capacitance $\left(c_{s}\right)$ of a synaptic vesicle is similar to that for other biological membranes, so that $\mathrm{c}_{\mathrm{s}} \approx 10 \mathrm{mF} \cdot \mathrm{m}^{-2}$ (Fettiplace et al., 1971; Albillos et al., 1997), we estimate the single vesicle capacitance at $45 \pm 11$ aF. However, synaptic vesicles contain an extraordinary number of transmembrane proteins (Takamori et al., 2006), so the true value of $\mathrm{c}_{\mathrm{s}}$ might be lower than that of typical cell membranes. Nevertheless, expression of a high density of transmembrane 
proteins in cultured cells has been shown not to alter the value of the specific membrane capacitance (Gentet et al., 2000).

In the foregoing estimate, we made no correction in our measurements of the vesicle diameter for possible distortion produced by conventional tissue preparation for electron microscopy (Tatsuoka and Reese, 1989). However, we note that synaptic vesicles preserved by highpressure rapid freezing, and examined by cryo-electron microscopy, have diameters identical to those prepared conventionally (Takamori et al., 2006).

\section{Discussion}

The complex anatomy of postsynaptic neurons complicates the analysis of electrical recordings, for some synaptic inputs lie at a greater electrotonic distance than others from the recording site (Bekkers and Stevens, 1996). At hair cell synapses, however, both the presynaptic and the postsynaptic elements are electrically compact. Using the hair cell synapses of the bullfrog's amphibian papilla, we have been able not only to conduct afferent fiber recordings to study postsynaptic currents but also to make hair cell capacitance measurements to examine the extent of presynaptic exocytosis.

\section{Paired recordings and the unitary charge transfer}

The amplitude histograms of spontaneous EPSCs under ordinary recording conditions show no substructure indicative of independently fusing vesicles. The effect of hyperpolarization suggests, however, that these synapses can release transmitter in smaller quantities that yield postsynaptic events of approximately $-50 \mathrm{fC}$. These EPSCs might represent the response to single vesicle fusion events. Our dual recordings, which relate the postsynaptic response to the change in presynaptic capacitance, offer a means of buttressing this conclusion by providing an independent estimate of the unitary charge transfer.

We wish to determine the mean postsynaptic charge transfer $q$ associated with the release of transmitter from a single vesicle, the fusion of which increases the presynaptic membrane's capacitance by an amount $c_{\mathrm{v}}$. If a protracted depolarization of a hair cell causes a measured increase $C$ in the presynaptic membrane capacitance and evokes a postsynaptic response with a total charge transfer $Q$, then we expect that

$$
\frac{q}{c_{\mathrm{v}}}=\left(\frac{P}{R}\right) \frac{Q}{C} \text { or } q=\left(\frac{\pi d^{2} c_{\mathrm{s}} P}{R}\right) \frac{Q}{C} .
$$

Here, $P$ is the probability that a vesicle's fusion occurs at a presynaptic active zone and can be sensed by the postsynaptic receptors, and $R$ is the innervation ratio of afferent fibers per stimulated hair cell. The fusion of a single vesicle increases the presynaptic capacitance by an amount $c_{\mathrm{v}}=\pi d^{2} c_{\mathrm{s}}$, in which $d$ is the diameter of a vesicle and $c_{\mathrm{s}}$ is the specific capacitance of the vesicle membrane; our electron microscopic results suggest that $c_{\mathrm{v}}=45 \mathrm{aF}$. If $P=R=1$, then the value of $Q / C=-1.01 \mathrm{kC} \cdot \mathrm{F}^{-1}$ adduced from our physiological measurements implies a unitary charge transfer of $q=-45 \mathrm{fC}$, a value in very good agreement with that obtained from histograms of the postsynaptic charge transfer during hair cell hyperpolarization to $-90 \mathrm{mV}$.

The foregoing analysis rests on two important assumptions. First, we suppose that most synaptic vesicles are released at presynaptic active zones so that $P \approx 1$. For hair cells acutely isolated from the bullfrog's sacculus, although, there is some ectopic exocytosis (Lenzi et al., 2002; Zenisek et al., 2003). If the same occurs for hair cells of the amphibian papilla, the value of $P$ might be less than unity. It is also possible that some afferent terminals are separated from their hair cells during dissection, again with the consequence of a lower value for $P$. The second assumption is that each depolarized hair cell contacts only the single afferent fiber involved in a simultaneous recording so that the innervation ra- 
A

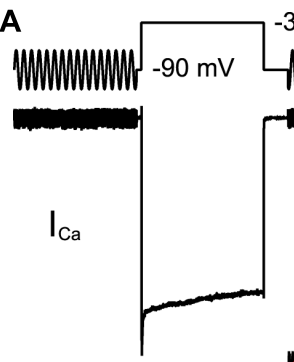

$-30 \mathrm{mV} \quad 1 \mathrm{kHz} \operatorname{sine}$

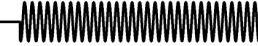

\begin{tabular}{l|l}
$\mathrm{C}_{\mathrm{m}}$ & $100 \mathrm{fF}$
\end{tabular}

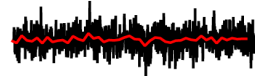

Nind
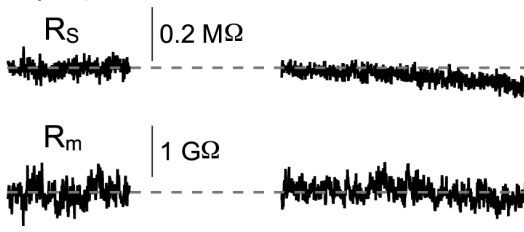

B

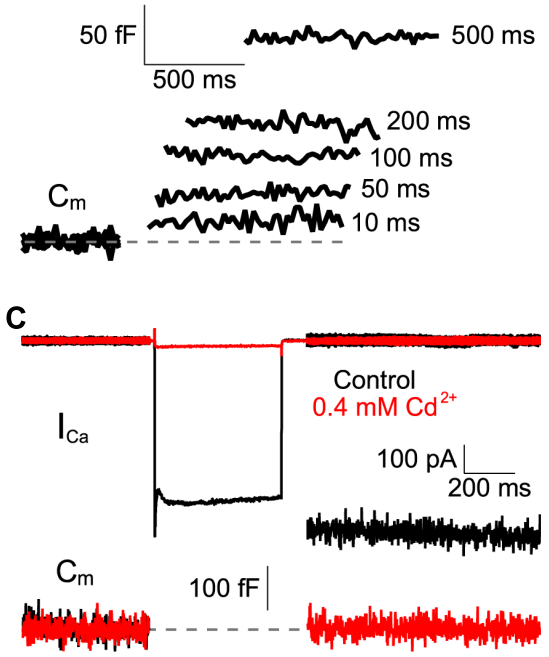

Figure 6. Presynaptic capacitance measurements. $\boldsymbol{A}$, A voltage-clamped hair cell was depolarized from a holding potential of $-90 \mathrm{mV}$ to $-30 \mathrm{mV}$ to evoke exocytosis. During the depolarizing stimulus, a presynaptic $\mathrm{Ca}^{2+}$ current $\left(I_{\mathrm{Ca}_{\mathrm{a}}}\right)$ was recorded. $\mathrm{A} 1 \mathrm{kHz}$ sinusoidal voltage $25 \mathrm{mV}$ in amplitude was superposed on the holding potential before and after the depolarization. From the measured current response to this signal, the membrane capacitance $\left(C_{\mathrm{M}}\right)$, series resistance $\left(R_{\mathrm{S}}\right)$, and membrane resistance $\left(R_{\mathrm{M}}\right)$ were calculated. The increase in capacitance reflects a rise in membrane surface area because of the fusion of synapticvesicles. The red trace is the averaged value of the capacitance data points. Note that the series resistance and membrane resistance remain constant. $\boldsymbol{B}$, The capacitance increases with the duration of the depolarizing stimulus. The traces shown are responses to single depolarizing pulses presented to the cell of panel $\boldsymbol{A}$. $\boldsymbol{C}$, $\mathrm{Cd}^{2+}$ at a concentration of $0.4 \mathrm{~mm}$ blocked both the $\mathrm{Ca}^{2+}$ current and the capacitance increase.
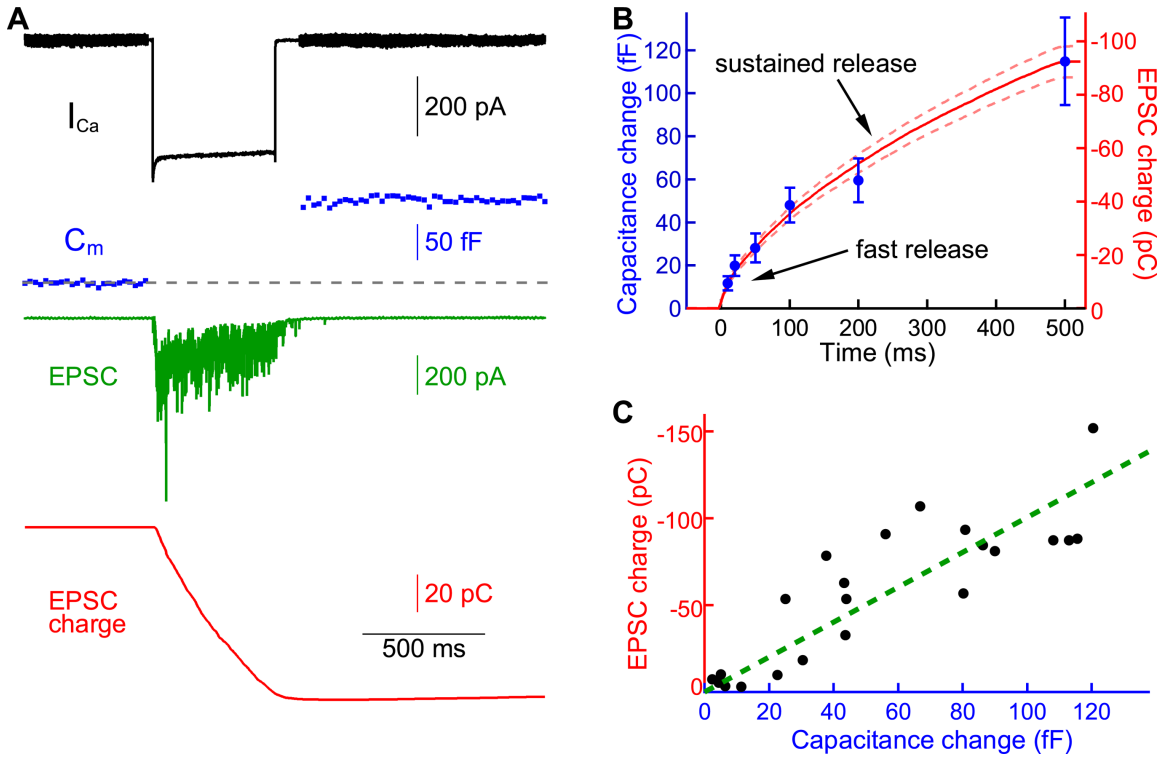

Figure 7. Paired recordings with capacitance measurements. $A$, In a representative hair cell afferent fiber paired recording, depolarization of the hair cell from -90 to $-30 \mathrm{mV}$ elicited a presynaptic $\mathrm{Ca}^{2+}$ current (black) and capacitance increase (blue) and a postsynaptic EPSC (green). The total charge transferred (red) is the integral of the evoked EPSC. B, The postsynaptic charge transferred (red, $n=11$; dashed lines indicate SE range) is well correlated with the increase in capacitance of the presynaptic membrane (blue; $n=6$ ) induced by depolarizing pulses of different durations. This agreement suggests that AMPA receptors are not significantly saturated or desensitized during exocytosis. C, For each paired recording, the total postsynaptic charge transferred was plotted against the presynaptic membrane capacitance increase. The data were fit with a straight line through the origin with a slope of $1.01 \mathrm{kC} \cdot \mathrm{F}^{-1}$ and a correlation coefficient of 0.86 .

tio $R \approx 1$. Several lines of evidence support the contention that each afferent fiber receives its input from but a single hair cell. In particular, holding the hair cell in a paired recording at a potential of $-90 \mathrm{mV}$ suppresses significantly the frequency of postsynaptic

activity, whereas the death of the hair cell interrupts all postsynaptic activity (data not shown). It is less certain, however, that each hair cell synapses with only a single afferent fiber; if this is not the case, $R$ might exceed unity. Remarkably enough, the uncertainties associated with these two assumptions make contributions in the same direction to our estimate of $q$. If $P$ were less than one or $R$ exceeded unity, the consequence would be that some of the measured change in presynaptic capacitance would not be associated with a detectable postsynaptic response. As a result, the true value of $q$-and thus the amplitude of the unitary postsynaptic current-could only be larger than suggested by our calculation. The critical point is that the actual value of $q$ is unlikely to be significantly smaller than we calculate. Our dual recordings, therefore, eliminate the greatest problem in most estimates of the magnitude of unitary events, namely that these events are so small that they are hidden in the noise of a recording.

Number of AMPA receptors activated by the fusion of one vesicle

Our estimate of the unitary response is reasonable in the light of other information about the ribbon synapses of hair cells. At the $-90 \mathrm{mV}$ holding potential of afferent fibers, this quantal size corresponds to a postsynaptic conductance of $\sim 600 \mathrm{pS}$. If each AMPA receptor at the ribbon synapse in the bullfrog's amphibian papilla has the conductance of $\sim 20 \mathrm{pS}$ observed for AMPA receptors in the auditory system (Parks, 2000; Sahara and Takahashi, 2001), the unitary response we measure involves the gating of $\sim 30$ receptors. The largest putatively multiquantal responses that we have encountered, with magnitudes near $-300 \mathrm{pA}$, would correspond to the activation of some 150 receptors. Freeze-fracture electron microscopy indicates that the postsynaptic membrane of afferent synapses in the mammalian cochlea is studded at a density of $3000 \mu \mathrm{m}^{-2}$ with large particles thought to be AMPA receptors (Saito, 1990). The afferent terminals at the ribbon synapse of the sacculus, another receptor organ of the bullfrog's internal ear, display intramembrane particles of a similar density (Jacobs and Hudspeth, 1990). In the region of the amphibian papilla under investigation, the postsynaptic membrane specialization at each ribbon synapse is $\sim 150$ $\mathrm{nm}$ across and $250 \mathrm{~nm}$ in length (Simmons et al., 1995; Keen and Hudspeth, 2006). If the membrane at this ribbon synapse holds AMPA receptors at the density observed by freeze-fracture electron microscopy, there are $\sim 110$ such receptors directly opposing each presynaptic active zone. The rough agreement between this value and that for the maximal receptor activation provides further sup- 
port for our estimate of the unitary response. A high density of AMPA receptors at the hair cell synapse avoids receptor saturation (Raghavachari and Lisman, 2004).

\section{Origin of large EPSCs at individual synaptic ribbons}

Because hair cells of the auditory papilla form several ribbon-type active zone sites onto one afferent terminal (Schnee et al., 2005; Keen and Hudspeth, 2006), large EPSCs could in principle represent the simultaneous fusion of single vesicles at different synaptic ribbons. However, brief, local iontophoresis of $\mathrm{Ca}^{2+}$ triggers large EPSCs (Fig. 3B). Furthermore, the differential block of small and large EPSCs by $\gamma$-DGG argues that large EPSCs do not originate from the simultaneous exocytosis of single quanta at different locations along the afferent terminal. Finally, the statistics of EPSC occurrence renders the probability that large EPSCs represent the random superposition of small EPSCs vanishingly small. Large events, therefore, originate at individual active zones through the release of glutamate onto a single postsynaptic cluster of AMPA receptors.

\section{Coordinated, compound, and cumulative exocytosis}

Our results demonstrate the occurrence in afferent fibers of unitary events of $-50 \mathrm{fC}$ in charge, or approximately $-57 \mathrm{pA}$ in amplitude. Whether recorded as spontaneous EPSCs or as components of evoked EPSCs, larger postsynaptic signals, therefore, represent the summation of several such unitary events. The usual response of approximately $-130 \mathrm{pA}$ implies the release of transmitter equivalent to two or three quanta; the largest events, approximately $-300 \mathrm{pA}$ in magnitude, correspond to the synchronous exocytosis of five or six quanta. Because we detected no temporal substructure in the waveforms of large events, we do not have evidence that they arise from independent vesicle fusions and cannot distinguish among three candidate mechanisms for the production of such signals: highly synchronous, cooperative fusion at distinct docking sites (Locke et al., 1999; Singer et al., 2004); compound fusion, in which several vesicles fuse together before undergoing exocytosis at a single site (Edmonds et al., 2004; Matthews and Sterling, 2008); and cumulative fusion, in which exocytosis by one docked vesicle initiates the rapid, piggyback fusion of several additional ones stacked along the ribbon (Hafez et al., 2003).

\section{Physiological role of multiquantal release}

The predominance of multiquantal release at hair cell synapses raises the question of the rationale for such an energetically expensive process. We propose two potential, and not necessarily mutually exclusive, explanations. In the auditory epithelium, a tonotopic array of hair cells provides finely graded frequency information to central processing centers. To prevent undue mixing of information between frequency channels, an afferent ordinarily receives input from only one or a few hair cells. With few active zones and docked vesicles available for signaling, the auditory system may compensate by raising the release probability at each active zone. Under these circumstances, multiquantal events may be merely a statistical consequence of the high release probability necessary for encoding sensory signals. An alternative possibility is that the size of presynaptic fusion events is dynamically regulated to encode signal intensity, provide precise phaselocked temporal information, or reduce the background noise that arises from the high sensitivity of auditory receptor cells. Further experiments will be needed to determine the contribution of multiquantal signaling to information transfer at this peripheral auditory synapse.

\section{References}

Albillos A, Dernick G, Horstmann H, Almers W, Alvarez de Toledo G, Lindau M (1997) The exocytotic event in chromaffin cells revealed by patch amperometry. Nature 389:509-512.

Angleson JK, Betz WJ (1997) Monitoring secretion in real time: capacitance, amperometry, fluorescence compared. Trends Neurosci 20:281-287.

Auger C, Marty A (2000) Quantal currents at single-site central synapses. J Physiol 526:3-11.

Bekkers JM, Stevens CF (1996) Cable properties of cultured hippocampal neurons determined from sucrose-evoked miniature EPSCs. J Neurophysiol 75:1250-1255.

Christie JM, Jahr CE (2006) Multivesicular release at Schaffer collateralCA1 hippocampal synapses. J Neurosci 26:210-216.

Clements JD, Bekkers JM (1997) Detection of spontaneous synaptic events with an optimally scaled template. Biophys J 73:220-229.

Crowley JJ, Carter AG, Regehr WG (2007) Fast vesicle replenishment and rapid recovery from desensitization at a single synaptic release site. J Neurosci 27:5448-5460.

Del Castillo J, Katz B (1954) Quantal components of the endplate potential. J Physiol 124:560-573.

Edmonds BW, Gregory FD, Schweizer FE (2004) Evidence that fast exocytosis can be predominantly mediated by vesicles not docked at active zones in frog saccular hair cells. J Physiol 560:439-450.

Fettiplace R, Andrews DM, Haydon DA (1971) The thickness, composition and structure of some lipid bilayers and natural membranes. J Membr Biol 5:277-296.

Forti L, Bossi M, Bergamaschi A, Villa A, Malgaroli A (1997) Loose-patch recordings of single quanta at individual hippocampal synapses. Nature 388:874-878.

Frerking M, Borges S, Wilson M (1997) Are some minis multiquantal? J Neurophysiol 78:1293-1304.

Furukawa T, Hayashida Y, Matsuura S (1978) Quantal analysis of the size of excitatory post-synaptic potentials at synapses between hair cells and afferent nerve fibres in goldfish. J Physiol 276:211-226.

Gelman A, Carlin JB, Stern HS, Rubin DB (2004) Bayesian data analysis, Ed 2. Boca Raton, FL: Chapman and Hall/CRC.

Gentet LJ, Stuart GJ, Clements JD (2000) Direct measurement of specific membrane capacitance in neurons. Biophys J 79:314-320.

Gillis KD (2000) Admittance-based measurement of membrane capaci- 
tance using the EPC-9 patch-clamp amplifier. Pflugers Arch 439:655-664.

Glowatzki E, Fuchs PA (2002) Transmitter release at the hair cell ribbon synapse. Nat Neurosci 5:147-154.

Goutman JD, Glowatzki E (2007) Time course and calcium dependence of transmitter release at a single ribbon synapse. Proc Natl Acad Sci U S A 104:16341-16346.

Griesinger CB, Richards CD, Ashmore JF (2005) Fast vesicle replenishment allows indefatigable signaling at the first auditory synapse. Nature 435:212-215.

Hafez I, Stolpe A, Lindau M (2003) Compound exocytosis and cumulative fusion in eosinophils. J Biol Chem 278:44921-44928.

Hallermann S, Pawlu C, Jonas P, Heckmann M (2003) A large pool of releasable vesicles in a cortical glutamatergic synapse. Proc Natl Acad Sci U S A 100:8975-8980.

Harata N, Pyle JL, Aravanis AM, Mozhayeva M, Kavalali ET, Tsien RW (2001) Limited numbers of recycling vesicles in small CNS nerve terminals: implications for neural signaling and vesicular cycling. Trends Neurosci 24:637-643.

Heidelberger R, Heinemann C, Neher E, Matthews G (1994) Calcium dependence of the rate of exocytosis in a synaptic terminal. Nature 371:513-515.

Heidelberger R, Thoreson WB, Witkovsky P (2005) Synaptic transmission at retinal ribbon synapses. Prog Retin Eye Res 24:682-720.

Henze DA, McMahon DB, Harris KM, Barrionuevo G (2002) Giant miniature EPSCs at the hippocampal mossy fiber to CA3 pyramidal cell synapse are monoquantal. J Neurophysiol 87:15-29.

Horrigan FT, Bookman RJ (1994) Releasable pools and the kinetics of exocytosis in adrenal chromaffin cells. Neuron 13:1119-1129.

Issa NP, Hudspeth AJ (1994) Clustering of $\mathrm{Ca}^{2+}$ channels and $\mathrm{Ca}^{2+}$ activated $\mathrm{K}^{+}$channels at fluorescently labeled presynaptic active zones of hair cells. Proc Natl Acad Sci U S A 91:7578-7582.

Jacobs RA, Hudspeth AJ (1990) Ultrastructural correlates of mechanoelectrical transduction in hair cells of the bullfrog's internal ear. Cold Spring Harb Symp Quant Biol 55:547-561.

Johnson SL, Marcotti W, Kros CJ (2005) Increase in efficiency and reduction in $\mathrm{Ca}^{2+}$ dependence of exocytosis during development of mouse inner hair cells. J Physiol 563:177-191.

Jonas P, Major G, Sakmann B (1993) Quantal components of unitary EPSCs at the mossy fibre synapse on CA3 pyramidal cells of rat hippocampus. J Physiol 472:615-663.

Keen EC, Hudspeth AJ (2006) Transfer characteristics of the hair cell's afferent synapse. Proc Natl Acad Sci U S A 103:5537-5542.

Korn H, Bausela F, Charpier S, Faber DS (1993) Synaptic noise and multiquantal release at dendritic synapses. J. Neurophysiol 70:1249-1254.

Lenzi D, Runyeon JW, Crum J, Ellisman MH, Roberts WM (1999) Synaptic vesicle populations in saccular hair cells reconstructed by electron tomography. J Neurosci 19:119-132.

Lenzi D, Crum J, Ellisman MH, Roberts WM (2002) Depolarization redistributes synaptic membrane and creates a gradient of vesicles on the synaptic body at a ribbon synapse. Neuron 36:649-659.

Lindau M, Neher E (1988) Patch-clamp techniques for time-resolved capacitance measurements in single cells. Pflugers Arch 411:137-146.

Llano I, González J, Caputo C, Lai FA, Blayney LM, Tan YP, Marty A (2000) Presynaptic calcium stores underlie large-amplitude miniature IPSCs and spontaneous calcium transients. Nat Neurosci 3:1256-1265.

Llobet A, Beaumont V, Lagnado L (2003) Real-time measurement of exocytosis and endocytosis using interference of light. Neuron 40:1075-1086.

Locke R, Vautrin J, Highstein S (1999) Miniature EPSPs and sensory encoding in the primary afferents of the vestibular lagena of the toadfish, Opsanus tau. Ann N Y Acad Sci 871:35-50.

Martin AR (1977) Junctional transmission II: presynaptic mechanisms. In: Handbook of physiology: a critical, comprehensive presentation of physiological knowledge and concepts, Sec 1, The nervous system, Vol 1, Cellular biology of neurons, Pt 1 (Kandel E, ed), pp 329-355. Bethesda, MD: American Physiological Society.

Matthews G, Sterling P (2008) Evidence that vesicles undergo compound fusion on the synaptic ribbon. J Neurosci 28:5403-5411.

Moser T, Beutner D (2000) Kinetics of exocytosis and endocytosis at the cochlear inner hair cell afferent synapse of the mouse. Proc Natl Acad Sci U S A 97:883-888.

Neef A, Khimich D, Pirih P, Riedel D, Wolf F, Moser T (2007) Probing the mechanism of exocytosis at the hair cell ribbon synapse. J Neurosci 27:12933-12944.

Neher E, Marty A (1982) Discrete changes of cell membrane capacitance observed under conditions of enhanced secretion in bovine adrenal chromaffin cells. Proc Natl Acad Sci U S A 79:6712-6716.

Nouvian R, Beutner D, Parsons TD, Moser T (2006) Structure and function of the hair cell ribbon synapse. J Membr Biol 209:153-165.

Pang JJ, Gao F, Barrow A, Jacoby RA, Wu SM (2008) How do tonic glutamatergic synapses evade receptor desensitization? J Physiol 586:2889-2902.

Parks TN (2000) The AMPA receptors of auditory neurons. Hear Res 147:77-91.

Parsons TD, Lenzi D, Almers W, Roberts WM (1994) Calcium-triggered exocytosis and endocytosis in an isolated presynaptic cell: capacitance measurements in saccular hair cells. Neuron 13:875-883.

Raghavachari S, Lisman JE (2004) Properties of quantal transmission at CA1 synapses. J Neurophysiol 92:2456-2467.

Rodriguez-Contreras A, Yamoah EN (2001) Direct measurement of singlechannel $\mathrm{Ca}^{2+}$ currents in bullfrog hair cells reveals two distinct channel subtypes. J Physiol 534:669-689.

Rossi ML, Martini M, Pelucchi B, Fesce R (1994) Quantal nature of synaptic transmission at the cytoneural junction in the frog labyrinth. J Physiol 478:17-35.

Rutherford MA, Roberts WM (2006) Frequency selectivity of synaptic exocytosis in frog saccular hair cells. Proc Natl Acad Sci U S A 103:2898-2903.

Sahara Y, Takahashi T (2001) Quantal components of the excitatory postsynaptic currents at a rat central auditory synapse. J Physiol 536:189-197.

Saito K (1990) Freeze-fracture organization of hair cell synapses in the sensory epithelium of guinea pig organ of Corti. J Electron Microsc Tech 15:173-186.

Sakaba T (2006) Roles of the fast-releasing and the slowly releasing vesicles in synaptic transmission at the calyx of Held. J Neurosci 26:5863-5871.

Schnee ME, Ricci AJ (2003) Biophysical and pharmacological characterization of voltage-gated calcium currents in turtle auditory hair cells. J Physiol 549:697-717.

Schnee ME, Lawton DM, Furness DN, Benke TA, Ricci AJ (2005) Auditory hair cell-afferent fiber synapses are specialized to operate at their best frequencies. Neuron 47:243-254.

Siegel JH (1992) Spontaneous synaptic potentials from afferent terminals in the guinea pig cochlea. Hear Res 59:85-92.

Silver RA, Cull-Candy SG, Takahashi T (1996) Non-NMDA glutamate receptor occupancy and open probability at a rat cerebellar synapse with single and multiple release sites. J Physiol 494:231-250.

Simmons DD, Bertolotto C, Leong M (1995) Synaptic ultrastructure within the amphibian papilla of Rana pipiens pipiens: rostrocaudal differences. Aud Neurosci 1:183-193.

Singer JH, Diamond JS (2006) Vesicle depletion and synaptic depression at a mammalian ribbon synapse. J Neurophysiol 95:3191-3198.

Singer JH, Lassová L, Vardi N, Diamond JS (2004) Coordinated multivesicular release at a mammalian ribbon synapse. Nat Neurosci 7:826-833.

Smotherman MS, Narins PM (2000) Hair cells, hearing and hopping: a field guide to hair cell physiology in the frog. J Exp Biol 203:2237-2246.

Spassova MA, Avissar M, Furman AC, Crumling MA, Saunders JC, Parsons TD (2004) Evidence that rapid vesicle replenishment of the synaptic ribbon mediates recovery from short-term adaptation at the hair cell afferent synapse. J Assoc Res Otolaryngol 5:376-390.

Starr PA, Sewell WF (1991) Neurotransmitter release from hair cells and its blockade by glutamate-receptor antagonists. Hear Res 52:23-41.

Sterling P, Matthews G (2005) Structure and function of ribbon synapses. Trends Neurosci 28:20-29.

Sun JY, Wu LG (2001) Fast kinetics of exocytosis revealed by simultaneous measurements of presynaptic capacitance and postsynaptic currents at a central synapse. Neuron 30:171-182.

Takamori S, Holt M, Stenius K, Lemke EA, Grønborg M, Riedel D, Urlaub H, Schenck S, Brügger B, Ringler P, Müller SA, Rammner B, Gräter F, Hub JS, De Groot BL, Mieskes G, Moriyama Y, Klingauf J, Grubmüller H, Heuser J, et al. (2006) Molecular anatomy of a trafficking organelle. Cell 127:831-846.

Tatsuoka H, Reese TS (1989) New structural features of synapses in the anteroventral cochlear nucleus prepared by direct freezing and freezesubstitution. J Comp Neurol 290:343-357. 
Tong G, Jahr CE (1994) Multivesicular release from excitatory synapses of cultured hippocampal neurons. Neuron 12:51-59.

von Gersdorff H, Matthews G (1994) Dynamics of synaptic vesicle fusion and membrane retrieval in synaptic terminals. Nature 367:735-739.

von Gersdorff H, Sakaba T, Berglund K, Tachibana M (1998) Submillisecond kinetics of glutamate release from a sensory synapse. Neuron 21:1177-1188.

Wadiche JI, Jahr CE (2001) Multivesicular release at climbing fiberPurkinje cell synapses. Neuron 32:301-313.

Wall MJ, Usowicz MM (1998) Development of the quantal properties of evoked and spontaneous synaptic currents at a brain synapse. Nat Neurosci 1:675-682.
Wen H, Brehm P (2005) Paired motor neuron-muscle recordings in zebrafish test the receptor blockade model for shaping synaptic current. J Neurosci 25:8104-8111.

Wölfel M, Lou X, Schneggenburger R (2007) A mechanism intrinsic to the vesicle fusion machinery determines fast and slow transmitter release at a large CNS synapse. J Neurosci 27:3198-3210.

Zenisek D, Davila V, Wan L, Almers W (2003) Imaging calcium entry sites and ribbon structures in two presynaptic cells. J Neurosci 23:2538-2548.

Zhang C, Zhou Z (2002) $\mathrm{Ca}^{2+}$-independnet but voltage-dependent secretion in mammalian dorsal root ganglion neurons. Nat Neurosci 5:425430. 